\title{
Necessity of Enzymatic Activity of Alkaline Phosphatase for Mineralization of Osteoblastic Cells
}

\author{
Yuki Sugawara $^{1, *}$, Kuniaki Suzuki ${ }^{2}$, Mino Koshikawa ${ }^{1}$, Masaki Ando ${ }^{1}$ and Junichiro Iida ${ }^{1}$ \\ ${ }^{1}$ Department of Oral Functional Science (Section of Orthodontics) and ${ }^{2}$ Department of Oral Pathobiological Science (Section of Dental \\ Pharmacology), Graduate School of Dental Medicine, Hokkaido University, Kita 13 Nishi 7, Kita-ku, Sapporo 060-8586, Japan
}

Received September 14, 2001 Accepted November 28, 2001

\begin{abstract}
Alkaline phosphatase (ALP) is supposed to be important for bone formation; however, its role is not clear. In this study, we examined the importance of enzymatic activity of ALP and anchoring of ALP protein to the cells for mineralization of an osteoblastic cell line, MC3T3-E1. While we cultured the cells in the presence of tetramisole, an inhibitor of ALP activity, ALP protein was expressed at a similar level to that in the control. Although tetramisole showed no effect on cell growth and increased hydroxyproline accumulation, it decreased the osteocalcin production and the accumulation of calcium and phosphate in the matrices. Tetramisole also inhibited mineralized nodule formation, which was observed by optical microscopy and detected by Von Kossa staining. On the other hand, when ALP protein was released from the cell membranes with the use of phosphatidylinositol-specific phospholipase $\mathrm{C}$, no marked changes were detected in hydroxyproline, calcium and phosphate accumulations in the matrices at late calcification stage, which was consistent with the morphological findings. These results clearly show that enzymatic activity of ALP is necessary for mineralization of MC3T3-E1 cells, but not the presence of ALP protein or anchoring of ALP to the cells.
\end{abstract}

Keywords: Alkaline phosphatase, Mineralization, Phosphatidylinositol-specific phospholipase C, Osteoblastic cell, Tetramisole

Bone-type alkaline phosphatase (ALP) is supposed to play a key role in the formation and calcification of hard tissues from accumulated circumstantial evidence (1). Although a number of theories have been proposed, its precise function is not well understood yet $(2-6)$. It is not even clear whether ALP is really indispensable to mineralization.

ALP is attached to the external surfaces of plasma membranes by phosphoethanolamine bound to oligosaccharide, which is, in turn, covalently linked to the polar head group of phosphatidylinositol (7-9). ALP is released from plasma membranes by phosphatidylinositol-specific phospholipase C (PIPLC) $(10-13)$.

We previously reported that ALPs of MC3T3-E1 cells were released into the medium during cell culture and the time course of the increase of ALP in the medium was consistent with the progress of mineralization (14). We assumed that matured and released ALP might be closely related to the mineralization. An alternative report demon-

*Corresponding author. FAX: +81-11-706-4928

E-mail: yuki_s@den.hokudai.ac.jp strated that ALP attached covalently to the external surface of plasma membranes was involved in the mineralization of hard tissues (15).

Our aim in this study was to clarify the importance of enzymatic activity of ALP and anchoring of ALP to the cells for mineralization. We used an osteoblastic cell line, MC3T3-E1 cells, which were established from fetal murine calvalial cells (16). The cells differentiate into osteoblasts and then produce ALP and process procollagens to collagens; finally the cells form mineralized tissues in vitro. We studied the effects of tetramisole, an inhibitor of ALP activity, and PIPLC additions to culture medium on mineralization of MC3T3-E1 cells. We report that enzymatic activity of ALP is important for mineralization of the cells.

\section{MATERIALS AND METHODS}

\section{Cell culture}

MC3T3-E1 cells, a mouse clonal osteoblastic cell line, are known to form multiple layers and to accumulate mineralized extracellular matrices (16). MC3T3-E1 cells were harvested by trypsinization and resuspended at 
$5 \times 10^{4}$ cells $/ \mathrm{ml}$. They $(0.5 \mathrm{ml}$ of resuspension $)$ were then seeded into each well of a 6-well tissue-culture plate and grown in an $\alpha$-minimum essential medium ( $\alpha$-MEM) supplemented with $10 \% \quad(\mathrm{v} / \mathrm{v})$ fetal bovine serum (F. Hoffman-La Roche Ltd., Basel, Switzerland) and kanamycine sulfate in a $5 \% \mathrm{CO}_{2}-95 \%$ air atmosphere at $37^{\circ} \mathrm{C}$. The medium in each dish was changed every $72 \mathrm{~h}$. The cells were harvested at 4, 13, 22, 31, 40 days after confluence and ultrasonicated, and the resultant homogenate was used for the experiments. The mineralization process of the cells was analyzed by biochemical assays, and representative data were obtained from three independent experiments.

\section{PIPLC treatment}

Eight $\mathrm{mU} / \mathrm{ml}$ PIPLC (Funakoshi, Tokyo) was added to the culture medium continuously from 1, 10 and 16 days after confluence to compel the cells to release ALP. Before harvesting the cells, the culture medium was recovered for analyses. The cells were washed with calcium- and magnesium-free Dulbecco's phosphate-buffered saline and harvested as described above.

\section{Treatment with tetramisole}

MC3T3-E1 cells were cultured as described above in the presence or absence (control) of $0.3 \mathrm{mM}$ tetramisole (Sigma, St. Louis, MO, USA). At 31 and 40 days after confluence, the culture medium was recovered and then the cells were harvested and ultrasonicated in $0.25 \mathrm{M}$ sucrose.

\section{ALP activity}

Enzymatic activities of ALP anchored or released were measured by an assay based on the method of Bessey et al. $(17,18)$. The basic reaction mixture contained $5 \mu \mathrm{l}$ of anchored enzyme fractions or $50 \mu \mathrm{l}$ of culture medium, $25 \mu \mathrm{mol}$ of carbonate, $12.5 \mathrm{mmol}$ of sucrose and $1 \mathrm{mmol}$ of $\mathrm{MgCl}_{2}$ in a total volume of $400 \mu \mathrm{l}(\mathrm{pH} 9.7)$; and the reaction was started by adding of $100 \mu \mathrm{l}$ of $10 \mathrm{mM}$-nitrophenylphosphate at $37^{\circ} \mathrm{C}$. The enzyme reaction was terminated by an addition of $1.5 \mathrm{ml}$ of $0.6 \mathrm{~N} \mathrm{NaOH}$ and the absorbance of $p$-nitrophenol ( $p$ NP) was read at $420 \mathrm{~nm}$. The value obtained from the medium with levamisole was subtracted from that without levamisole as a background level.

\section{Other measurements}

The amount of hydroxyproline was measured for estimation of collagen accumulated in the cell matrices. The cells and matrices were removed from each well and hydrolyzed with $6 \mathrm{~N} \mathrm{HCl}$ at $110^{\circ} \mathrm{C}$ for $24 \mathrm{~h}$. $\mathrm{HCl}$ was removed with a rotary evaporator and the resultant hydrolysate was dissolved in water and used as a sample. Then the samples were analyzed by the Woessner method described in the previous paper (14).

The accumulation of calcium and phosphate was measured for assessment of the mineralization. The hydrolysate obtained for hydroxyproline measurement was transferred into a porcelain crucible and burnt to ashes for $18 \mathrm{~h}$ at $750^{\circ} \mathrm{C}$. The ashes were dissolved in $5 \%(\mathrm{v} / \mathrm{v}) \mathrm{HCl}$ containing $1 \%(\mathrm{w} / \mathrm{v}) \mathrm{LaCl}_{3}$ and calcium was assayed with the use of atomic absorbance spectrophotometer (19). For measurement of phosphate, the ashes were dissolved in water and assayed by the method of Chifflet et al. (20).

The amount of osteocalcin released into the culture medium was measured by radioimmunoassay according to the method recommended by the manufacturer (Biomedical Technologies, Inc., Stoughton, MA, USA).

Protein concentration was measured with the Bio-Rad DC protein assay kit (Bio Rad, Hercules, CA, USA) using bovine serum albumin as standard.

\section{Statistical analyses}

Data obtained were subjected to the $F$-test and then the Student's $t$-test.

\section{RESULTS}

\section{Effects of tetramisole treatment on ALP activity}

We tested the concentration-dependency of tetramisole in its effects on cell-anchored ALP and released ALP into the medium. Activities of both anchored and released ALPs were inhibited by tetramisole at a similar concentration $\left(\mathrm{k}_{\mathrm{i} 0.5}<100 \mu \mathrm{M}\right)$ (Fig. 1a). The inhibition was almost complete at $4 \mathrm{mM}$; this concentration of tetramisole was found to be cytotoxic and inhibited the growth of E1 cells. We cultured the cells in the presence of $0.3 \mathrm{mM}$ tetramisole, a concentration that inhibits about $90 \%$ of ALP activity. Then we measured ALP activity anchored to the cells to test the expression of ALP protein. The ALP activities after cells were washed three times were almost at a similar level to those of the cells cultured without tetramisole (Fig. 1b).

\section{Effects of tetramisole on mineralization of MC3T3-E1 cells}

An addition of $0.3 \mathrm{mM}$ tetramisole into the culture medium did not affect either the cell growth under microscopic observation or the protein content of the cell homogenates during culture (Fig. 2a). However, the tetramisole treatment clearly decreased the accumulation of calcium (Fig. 2b) and phosphate (Fig. 2c) in the matrices and also decreased the production of osteocalcin in the medium (Fig. 2d). On the other hand, the treatment increased the accumulation of hydroxyproline in the matrices (Fig. 2e). 

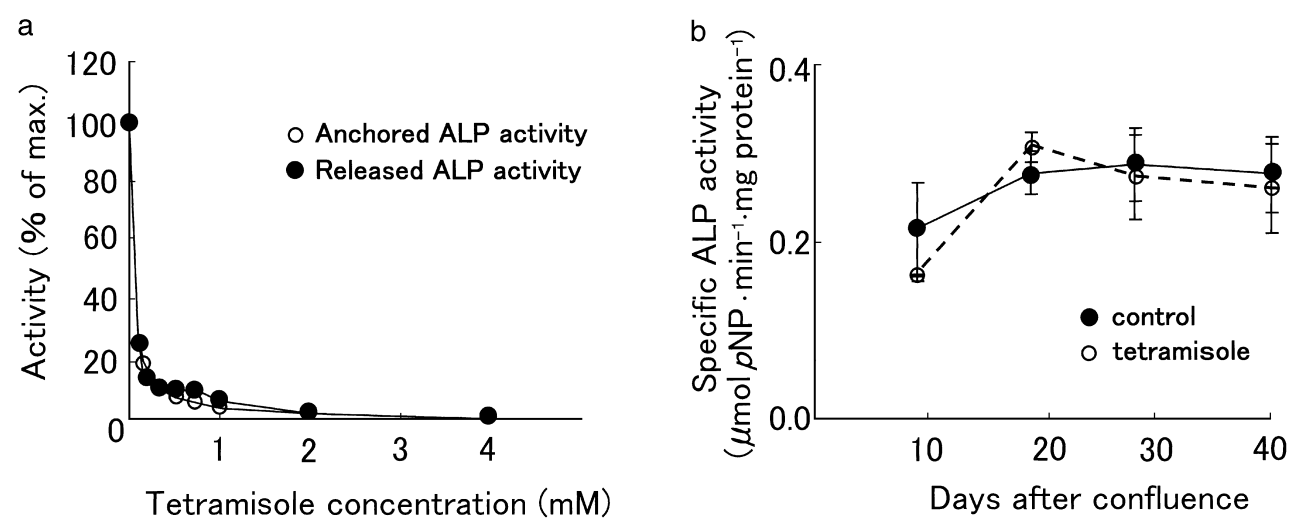

Fig. 1. Effects of tetramisole on anchored and released ALP activities of MC3T3-E1 cells. a: MC3T3-E1 cells were grown in $\alpha$-MEM for 28 days after confluence. After culture medium was recovered, the cells were homogenized as described in the Materials and Methods. Concentration-dependency of tetramisole inhibition of ALP activities was tested in the cell homogenate (open circles) and the cultured medium (closed circles). The results are expressed as a percentage of maximum activity. b: The effects of tetramisole treatment on anchored ALP activity. The cells were grown without (control) or with $0.3 \mathrm{mM}$ tetramisole for the days indicated in the figure, and then the cells were washed three times with $0.25 \mathrm{M}$ sucrose in the wells. After the cells were recovered by using a scraper, they were washed three more times by centrifugation. ALP activities were assayed with the use of both cell homogenates. The data represent the mean \pm S.D. of 6 wells.

Effects of tetramisole on the morphology of MC3T3-E1 cells

In the absence of tetramisole, MC3T3-E1 cells formed multilayered structures during cell culture and then colonies with clusters of the characteristic spherical cells at about 20 days after confluence under the optical microscope. The colonies gradually changed to mineralized nodules and the nodular structure intensified in density at 40 days after confluence (Fig. 3a). When the cells were cultured in the presence of $0.3 \mathrm{mM}$ tetramisole, formation of mineralized nodules was not observed (Fig. 3b). This was also confirmed by Von Kossa staining (Fig. 3, c and d). The mineralized particles were stained black in the absence of tetramisole, whereas no mineralized particles were observed in the presence of tetramisole.

\section{Changes in ALP activity by PIPLC treatment during cell culture}

Next we tested whether anchoring of ALP to the cell membrane was important for mineralization by using PIPLC that releases ALP from the cells. MC3T3-E1 cells were cultured with and without (control) $8 \mathrm{mU} / \mathrm{ml}$ PIPLC, and ALP activities anchored to the cells and in the medium were measured. An addition of PIPLC was started from 1, 10 and 16 days after confluence. In the absence of PIPLC, ALP activity anchored to the cells increased at 5 days after confluence and reached a markedly high level at 20 days, whereas little ALP activity was observed in its presence (Fig. 4). Most of the activity in the presence of PIPLC was released into the medium irrespective of the days of additions.
Effects of PIPLC additions on the markers of mineralization of MC3T3-E1 cells

The continuous PIPLC addition showed no significant effects on the protein content irrespective of the days of additions (Fig. 5a). The continuous addition of PIPLC started 1 day after confluence slightly decreased the production of hydroxyproline, but those started 10 and 16 days after showed no significant effects (Fig. 5b). The PIPLC additions decreased osteocalcin production at 31 days of culture, but the difference between the control and those with PIPLC additions lessened at 40 days (Fig. 5c). The effects of PIPLC on calcium accumulations slightly varied, and no clear differences were observed among the control and those with PIPLC additions (Fig. 5d). The addition of PIPLC slightly decreased the accumulation of phosphate (Fig. 5e) at 31 days, but no significant difference was observed at 40 days.

\section{Effects of PIPLC on the morphology of MC3T3-E1 cells}

As described above, MC3T3-E1 cells formed mineralized nodules as determined under the optical microscope. We examined the morphological effects of PIPLC on the cells that were compelled to release ALP into the medium. The continuous PIPLC treatment started 1 day after confluence did not affect mineralized nodule formation. However, when the treatments were started 10 and 16 days after confluence, clearly mineralized nodule formation was not observed (data not shown).

\section{DISCUSSION}

ALP activity is increased in accordance with osteoblastic 

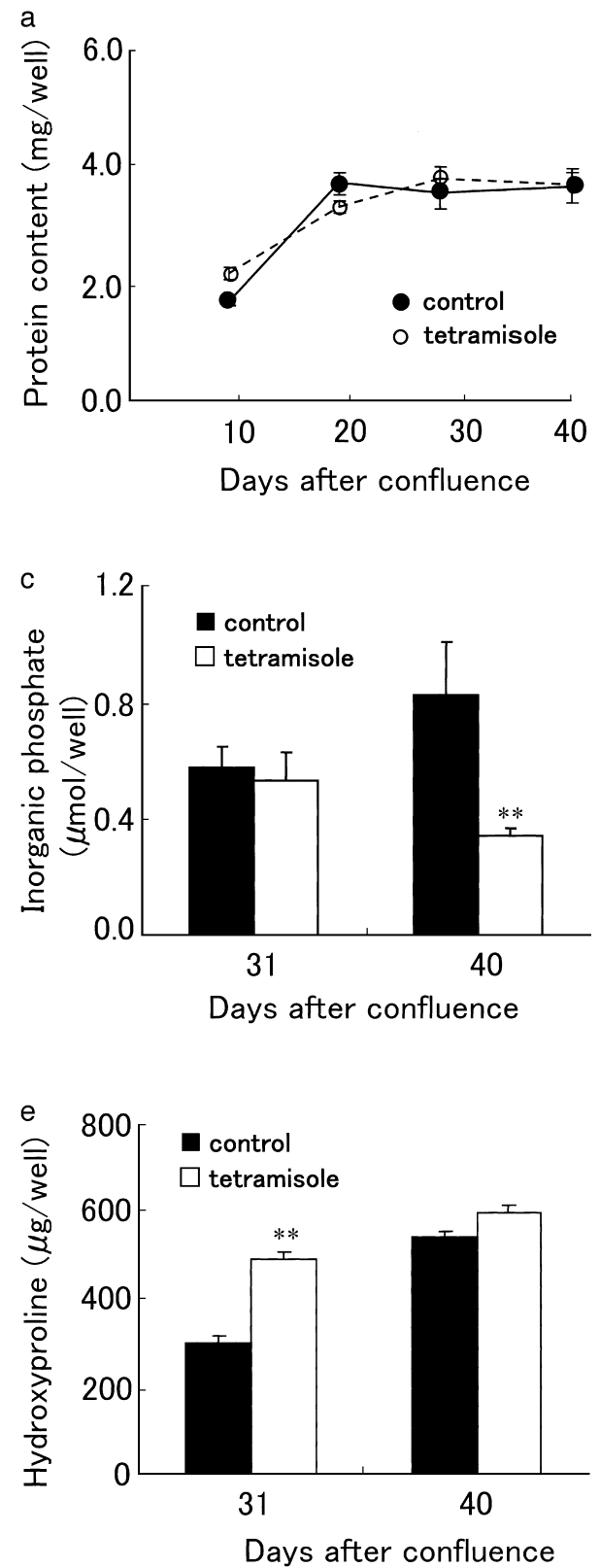

differentiation in bone tissue. Although many hypotheses have been proposed about the functions of ALP for mineralization $(2-6)$, the functions have not been elucidated. Thomas and Ramp reported that inhibition of ALP activity by levamisole, a specific inhibitor of ALP activity, caused the inhibition of bone mineral accumulation with use of cultured chick embryo tibiae (21). To confirm the necessity of ALP activity for mineralization, we tested the effects of tetramisole, which is also a specific noncompetitive inhibitor of ALP activity and a mixture of levamisole and dexamisole, an optical isomer of levamisole (22), on mineralization of osteoblastic MC3T3-E1 cells. When the cells were cultured in the presence of $0.3 \mathrm{mM}$ tetramisole, b
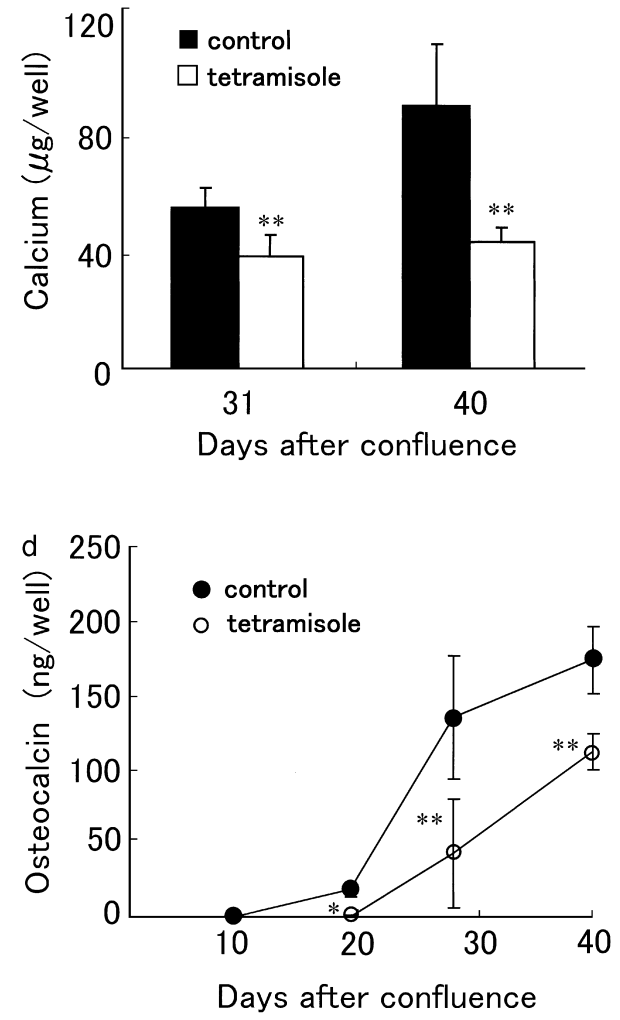

Fig. 2. Effects of tetramisole treatment on protein content, calcium, phosphate, osteocalcin and hydroxyproline. The cells were grown without (control) or with $0.3 \mathrm{mM}$ tetramisole for the days indicated in the figures. The amounts of protein (a), calcium (b), phosphate (c) and hydroxyproline (e) were measured with the use of cell homogenates as described in the Materials and Methods. The amount of osteocalcin (d) was measured by radioimmunoassay of the culture medium. The data represent the mean \pm S.D. of 6 wells. $* P<0.05$ and $* * P<0.01$ versus control (Student's $t$-test).

which was a concentration sufficient to inhibit the ALP enzymatic activity without cytotoxicity, no mineralized nodule was observed under the optical microscope (Fig. 3). This observation was supported by biochemical measurements of phosphate, calcium and osteocalcin (Fig. 2). It was ascertained that ALP was fully expressed in the presence of tetramisole (Fig. 1). These results strongly suggest that hydrolysis activity of ALP is necessary for the calcification. The exact role of ALP for mineralization and the substrates for enzymatic activity of ALP have not been determined in this study. However, tetramisole did increase the accumulation of hydroxyproline in the matrices (Fig. 2e). Although the reason for the increase remains to 
a

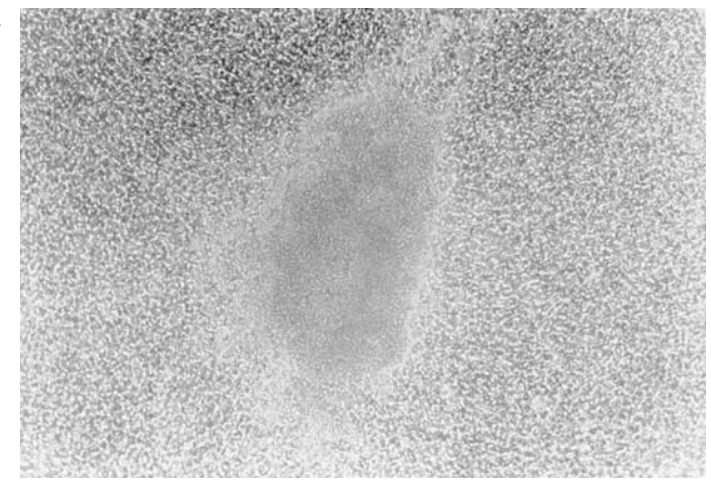

$\mathrm{C}$

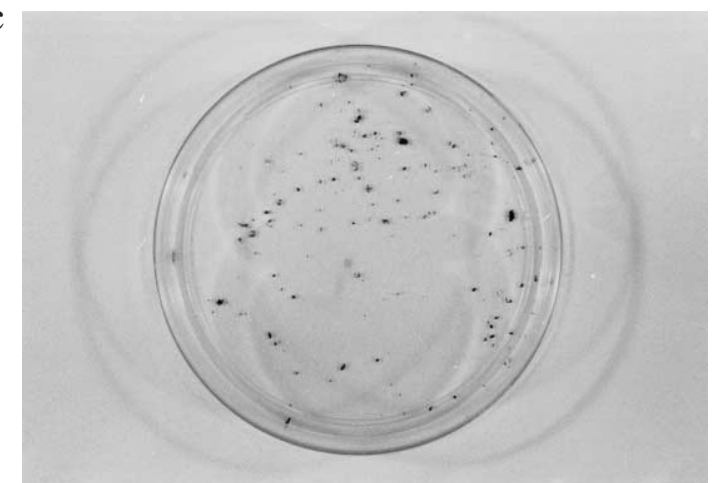

b

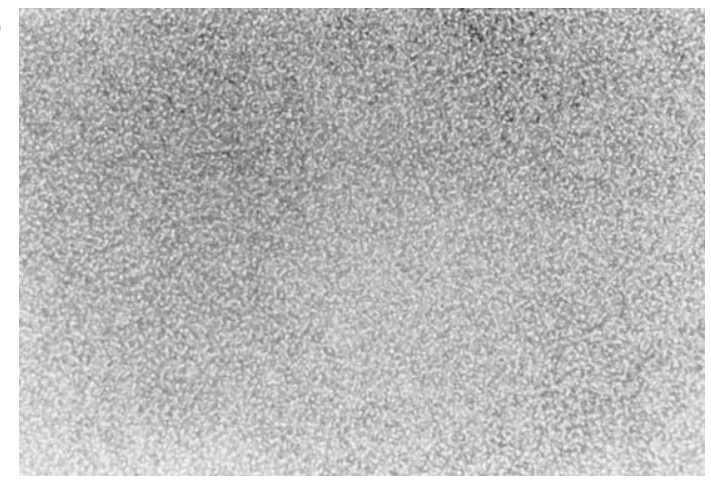

d

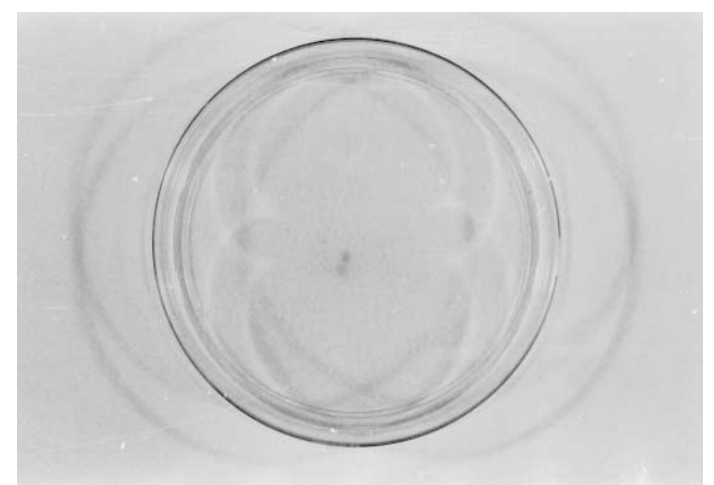

Fig. 3. Effects of tetramisole treatment on microscopic observation of MC3T3-E1 cells. The cells were cultured in $\alpha$-MEM without (control, a and c) or with $0.3 \mathrm{mM}$ tetramisole (b and d) (bar, $100 \mu \mathrm{m}$ ). The cells were observed at 40 days after confluence as determined under the optical microscope ( $a$ and b). The cells were also observed at 40 days after Von Kossa staining (c and d).

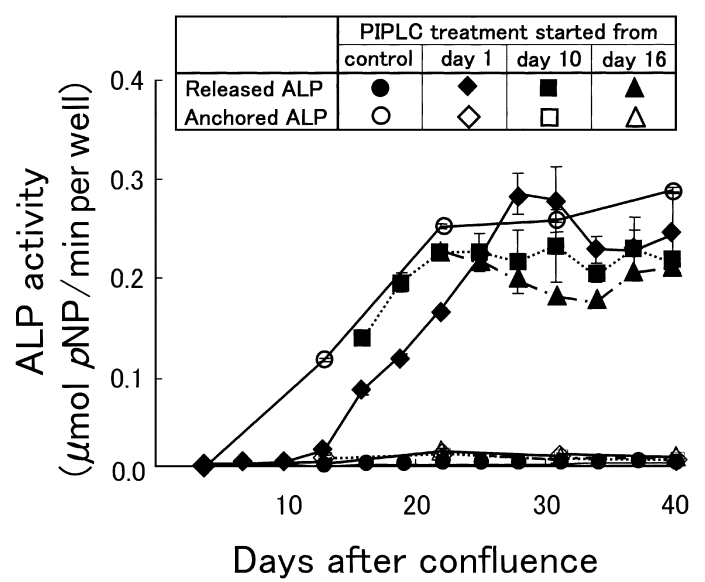

Fig. 4. Effects of PIPLC treatment on the changes in ALP activity of MC3T3-E1 cells. The cells were cultured in $\alpha$-MEM without (circles) or with $8 \mathrm{mU} / \mathrm{ml}$ PIPLC (diamonds, squares and triangles). The additions of PIPLC were started from day 1, 10 and 16 after confluence, and it was added continuously thereafter. The culture media were recovered and the cell homogenates were prepared on the days indicated on the figures. The activities of anchored and released ALP were measured as described in Materials and Methods. The data represent the mean \pm S.D. of 6 wells. be elucidated, this finding may suggest that the process of mineral deposition and the production of matrix proteins are regulated by different mechanisms. ALP may be involved in the extracellular breakdown of pyrophosphate, a potent inhibitor of calcium and phosphate deposition, and therefore may play a crucial role in skeletal mineralization (1).

Next we tested the necessity of anchoring of ALP to the plasma membrane for mineralization. ALP is an ectoenzyme anchored to plasma membranes via a glycosyl phosphatidylinositol (GPI) anchor (7 - 9). This enzyme can be released into the circulation by a phosphatidylinositolglycan hydrolase $(10-13)$. There is a phosphatidylinositol-glycanspecific phospholipase D (PIPLD) in human and bovine sera (23), and the enzyme may control the amount of ALP anchored to the membrane by releasing it. In vitro, it is reported that ALP anchored to the membrane can be released by PIPLC treatment $(8,15)$. It is also reported that an increase of ALP activity naturally released from osteoblastic MC3T3-E1 cells into medium might be closely related to their mineralization during cell culture (14). On the other hand, it is reported that bone ALP could participate in the calcification process only in its GPI-anchored 


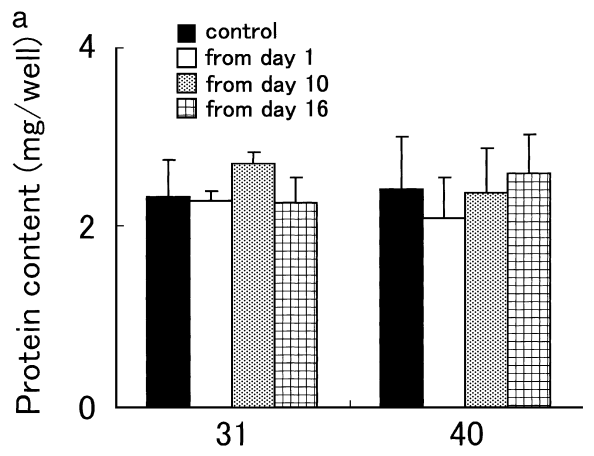

Days after confluence
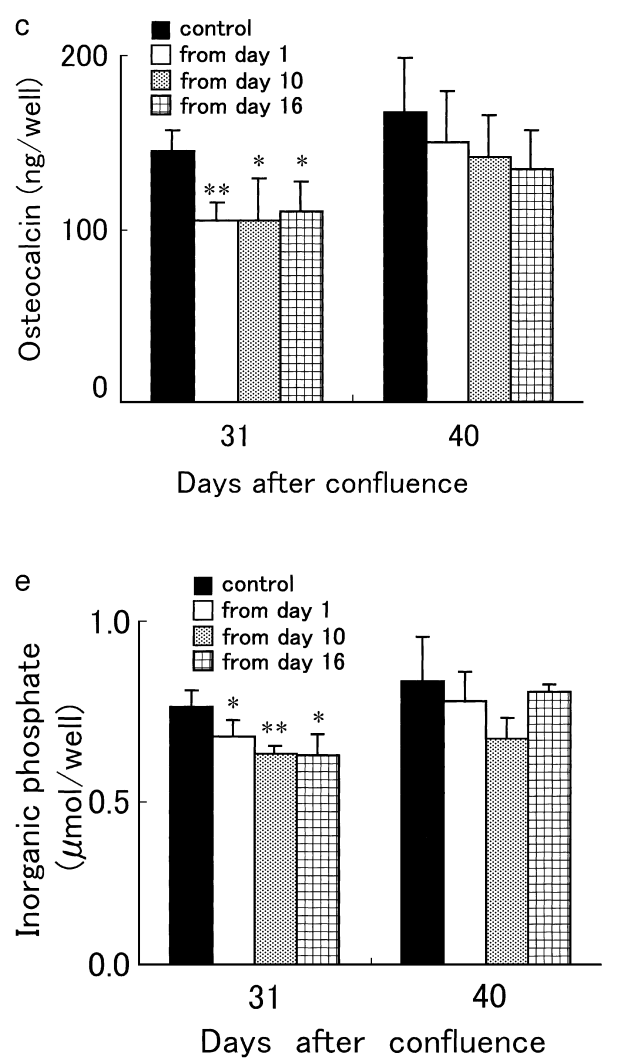

form $(24,25)$. As the reports are controversial (15), we investigated the effects of release of ALP from the plasma membrane on mineralization of MC3T3-E1 cells. The continuous PIPLC treatment compelled the cells to release anchored ALP into the culture medium. This treatment did not significantly change the accumulation of calcium and phosphate, or the production of hydroxyproline and osteocalcin at 40 days, irrespective of its starting days (Fig. 5). Morphological observation of the cells treated with PIPLC from 1 day after confluence supported the results of biochemical measurements. These results suggest that the state of ALP, whether it is bound to the cells or released to the medium, was not important for differentiation to osteo-
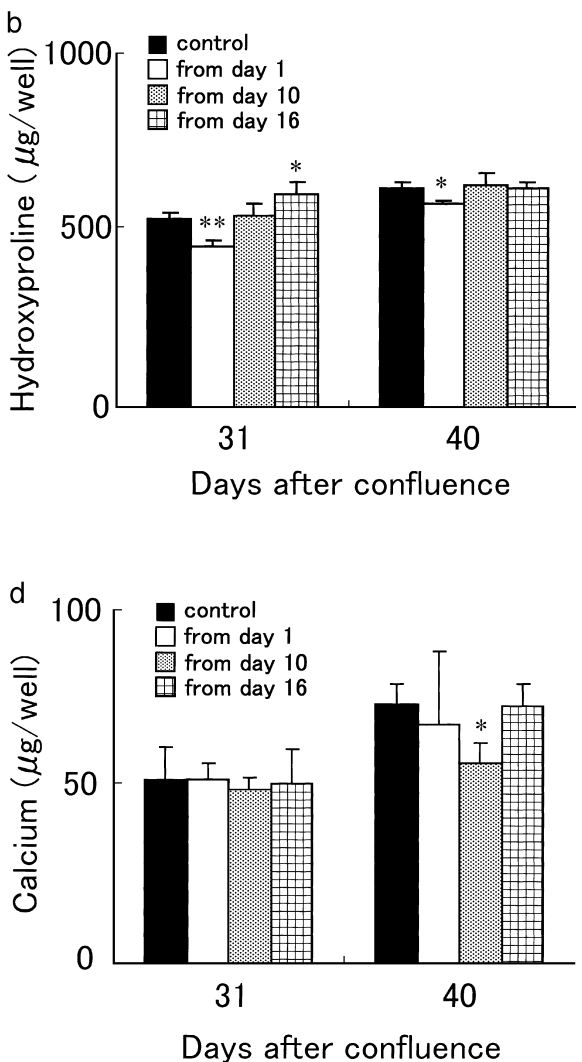

Fig. 5. Effects of PIPLC treatment on protein, hydroxyproline, osteocalcin, calcium and phosphate. The cells were grown without (control) or continuously with $8 \mathrm{mU} / \mathrm{ml}$ PIPLC for 31 or 40 days. The additions of PIPLC were started from day 1,10 and 16 after confluence. The culture media were recovered and the cell homogenates were prepared at 31 or 40 days after confluence. The amounts of protein (a), hydroxyproline (b), calcium (d) and phosphate (e) were measured with the use of cell homogenates as described in the Materials and Methods. The amount of osteocalcin (c) was measured by radioimmunoassay of the culture medium. The data represent the mean \pm S.D. of 6 wells. $* P<0.05$ and $* * P<0.01$ versus control (Student's $t$-test).

blasts, formation of extracellular matrices or accumulation of calcium and phosphate. ALP in the medium might hydrolyze the substrates as ALP anchored to the cells did, or released ALP might be transported to matrix vesicles to function as an enzyme. We had assumed that released ALP might be closely related to mineralization of MC3T3-E1 cells in our previous study (14), but the assumption was not supported by the experiments described here.

Inconsistent with our results, Togari et al. (15) reported that ALP bound to the cell membrane was important for mineralization, and Hsu et al. (26) and Wong and Low (27) reported that treatment of PIPLC reduced mineral to about $80 \%$. There is one thing to be noted to explain the gap. 
When PIPLC treatment was started 10 and 16 days after confluence, clearly mineralized nodule formation was not observed under the optical microscope in spite of little difference in biochemical measurements. Harisson et al. (28) tested the ability of ALP with and without GPI anchors to drive mineral formation. Both of them showed similar enzymatic activity to hydrolyze $\beta$-glycerol phosphate and promoted mineralization, but scanning electron microscopy and $\mathrm{x}$-ray microanalysis revealed that the mineral produced by anchored ALP was more apatite-like than mineral formed by ALP without GPI anchor. They concluded that ALP with GPI anchor is a more effective initiator of biological mineralization than ALP without GPI anchor. ALP anchored and concentrated to the cell layers might be necessary for the nodule formation in vitro. Another possibility would be that some other GPI anchoring protein released by PIPLC had lost the function to form mineralized nodules.

Our conclusion is that enzymatic hydrolysis activity of ALP is necessary to form mineralized tissue and that anchoring of ALP to the cell membrane is not always necessary for mineralization, but may affect the nodule formation in vitro.

\section{Acknowledgments}

We wish to thank Dr. S. Nishikata, Dr. Y. Yoshimura, Dr. Y. Deyama, Dr. M. Hatta and Dr. T. Kajii (Hokkaido University) for their assistance in this research.

\section{REFERENCES}

1 Whyte MP and Vrabel LA: Infantile hypophosphatasia fibroblasts proliferate normally in culture: evidence against a role for alkaline phosphatase (tissue nonspecific isoenzyme) in the regulation of cell growth and differentiation. Calcif Tissue Int 40, 1 - 7 (1987)

2 Robisson R: The possible significance of hexosephosphoric esters in ossification. Biochem J 17, 286 - 293 (1923)

3 Fleish H and Newman WF: Mechanisms of calcification: role of collagen, polyphosphates and phosphatase. Am J Physiol 200, 1296 - 1300 (1961)

4 Wuthier RE, Bisaz S, Russell RGG and Fleisch H: Relationship between pyrophosphate, amorphous calcium phosphate and other factors in the sequence of calcification in vitro. Calcif Tissue Res 10, 198 - 206 (1972)

5 DeBernard B, Bianco B, Bonucci E, Constantini M, Lunazzi, GC, Martinuzzi P, Modridky C, Molo L, Panfili E, Pollesello P, Stagni $\mathrm{N}$ and Vittur F: Biochemical and immunohistochemical evidence that in cartilage an alkaline phosphatase is a $\mathrm{Ca}^{2+}$ binding glycoprotein. J Cell Biol 103, 1615 - 1623 (1986)

6 Fedde KN and Whyte MP: Alkaline phosphatase (tissue-nonspecific isoenzyme) is a phospho ethanolamine and pyridoxal-5'phosphate ectophosphatase: normal and hypophosphatasia fibroblast study. Am J Hum Genet 47, 767 - 775 (1990)

7 Ikezawa H, Yamanegi M, Taguchi R, Miyashita T and Ohyabu T: Studies on phosphatidylinositol phosphodiesterase (phospholipase $\mathrm{C}$ type) of Bacillus cereus. Biochim Biophys Acta 450,
$154-164$ (1976)

8 Low MG and Zilversmit DB: Role of phosphatidylinositol in attachment of alkaline phosphatase to membranes. Biochemistry 19, 3913-3918 (1980)

9 Hopper NM and Turner AJ: Ectoenzymes of the kidney microvillar membrane. Aminopeptidase $\mathrm{P}$ is anchored by a glycosyl-phosphatidylinositol moiety. FEBS Lett 229, $340-$ 344 (1988)

10 Harris H: The human alkaline phosphatases: what we know and what we don't know. Clin Chim Acta 186, 133 - 150 (1989)

11 Low MG and Saltiel AR: Structural and functional roles of glycosyl-phosphatidylinositol in membranes. Science 239, 268 275 (1988)

12 Farley JR, Hall SL, Herring S, Libanati C and Wergedal JE: Reference standards for quantification of skeletal alkaline phosphatase activity in serum by heat inactivation and lectin precipitation. Clin Chem 39, 1878 - 1884 (1993)

13 Farley JR and Jorch UM: Differential effects of phospholipids on skeletal alkaline phosphatase activity in extracts, in situ and in circulation. Arch Biochem Biophys 221, 447 - 488 (1983)

14 Yoshikawa M, Suzuki K, Kajii T, Koshikawa M, Imai T and Matsumoto A: Quantitative analysis of alkaline phosphatase activity and mineralization of a clonal osteoblast-like cell MC3T3-E1. J Hard Tissue Biol 8, 37 - 42 (1999)

15 Togari A, Arakawa S, Arai M and Matumoto S: Inhibition of in vitro mineralization in osteoblastic cells and in mouse tooth germ by phosphatidylinositol-specific phospholipase C. Biochem Pharmacol 46, 1668 - 1670 (1993)

16 Sudo H, Kodama HA, Amagai Y, Yamamoto S and Kasai S: In vitro differentiation and calcification in a new clonal osteogenic cell line derived from newborn mouse calvaria. J Cell Biol 96, 191 - 198 (1983)

17 Suzuki K, Yoshimura Y, Hisada Y and Matsumoto A: Sensitivity of intestinal alkaline phosphatase to L-homoarginine and its regulation by subunit-subunit interaction. Jpn J Pharmacol 64, $97-102$ (1994)

18 Bessey OA, Lowry OH and Brock MJ: A method for the rapid alkaline phosphatase with five cubic millimeters of serum. J Biol Chem 164, 321 - 329 (1946)

19 Corradino RA, Ebel JG, Craig PH, Taylor AN and Wasserman RH: Calcium absorption and the vitamin D3-dependent calciumbinding protein. 1. Inhibition by dietary strontium. Calcif Tissue Res 7, 81 - 92 (1971)

20 Chifflet S, Torriglia A, Chiesa R and Tolosa S: A method for the determination of inorganic phosphate in the presence of labile organic phosphate and high concentrations of protein: application to lens ATPases. Anal Biochem 168, 1 - 4 (1988)

21 Thomas ML and Ramp WK: Effects of parathyroid hormone on alkaline phosphatase activity and mineralization of cultured chick embryo tibiae. Calcif Tissue Int 27, 137 - 142 (1979)

22 McComb RB, Bowers GN Jr and Posen S: Reaction mechanisms. In Alkaline Phosphatase, Edited by McComb RB, Bowers GN Jr and Posen S, pp 229-287, Plenum Press, New York (1979)

23 Scallon BJ, Fung WJC, Tsang TC, Li S, Kado-Fong H, Huang KS and Kochan JP: Primary structure and functional activity of a phosphatidylinositol-glycan-specific phospholipase D. Science 252, 446 - 448 (1991)

24 Collin P, Nefussi JR, Wetterwald A, Nicolas V, Boy-Lefevre ML, Fleish H and Forest N: Expression of collagen, osteocalcin, 
and bone alkaline phosphatase in a mineralizing rat osteoblastic cell culture. Calcif Tissue Int 50, 175 - 183 (1992)

25 Nosjean O, Briolay A and Rox B: Mammalian GPI proteins: sorting, membrane resistance and functions. Biochim Biophys Acta 1331, 153 - 186 (1997)

26 Hsu HH, Morris DC, Davis L, Moylan P and Anderson CH: In vitro $\mathrm{Ca}$ deposition by rat matrix vesicles: is the membrane association of alkaline phosphatase essential for matrix vesicle- mediated calcium deposition? Int J Biochem 25, 1737-1742 (1993)

27 Wong YW and Low MG: Phospholipase resistance of the glycosyl-phosphatidylinositol membrane anchor on human alkaline phosphatase. Clin Chem 38, 2517 - 2525 (1992)

28 Harrison G, Shapiro IM and Golub EE: The phosphatidylinositol-glycolipid anchor on alkaline phosphatase facilitates mineralization in vitro. J Bone Miner Res 10, 598 - 573 (1995) 